\title{
Fatty Acid Methyl Ester of Nigerian Spent Palm and Peanut Oils: Non-Food Option for Biodiesel to Safe Food Security and Environment (Part I)
}

\author{
*MOYIB, OK; OMOTOLA, OE
}

\author{
Department of Chemical Sciences, Tai Solarin University of Education, Ijagun. PMB 2118, Ijebu-Ode Nigeria \\ *Corresponding Author: kmoyib@hotmail.com; moyibok@tasued.edu.ng; M-Phone: +234(0)7019595255, 09063491211
}

\begin{abstract}
In the awakening of Nigeria biofuel economy and reduced carbon footprint revolution, her targeted feedstocks such as sweet sorghum and palm oil are hidden threat to food security. To avoid this scenario, the present study derived fatty acid methyl esters (FAME) from Nigerian spent palm and peanut oils (NSPO and NSPeO) as cheap and non-food feedstocks for biodiesel and safe environment. Fresh and spent Nigerian palm oil (NPO) and peanut oil $\left(\mathrm{NP}_{\mathrm{e}} \mathrm{O}\right)$ were converted into FAME by one and two steps alkali transesterification using 6:1 molar ratio of methanol to oil, $1.0 \%$ wt. potassium hydroxide pellets as catalyst at $60^{\circ} \mathrm{C}$ over $1 \mathrm{hr}$. Characterization of feedstocks and FAME were carried out using European (EN) and USA (ASTM) norms for quality biodiesel. The quality of final FAME obtained after two-steps alkali transesterification were within international norms for biodiesel except for alkali and alkaline earth metals that required further removal using adsorption process as a post-transesterification treatment. The present study reveals Nigerian spent palm and peanut oils as potential non-food feedstocks for biodiesel production to safe food security and environment.
\end{abstract}

\section{DOI: https://dx.doi.org/10.4314/jasem.v22i5.35}

Copyright: Copyright $\left({ }^{\circ} 2018\right.$ Moyib and Omotola. This is an open access article distributed under the Creative Commons Attribution License (CCL), which permits unrestricted use, distribution, and reproduction in any medium, provided the original work is properly cited.

Dates: 09 January, 2018, Revised: 02 May 2018, Accepted: 05 May 2018

Key words: Alkali-transesterification, fatty acid methyl ester, food security, Nigerian spent palm

Nigeria needs to prepare for post-fossil fuel future to achieve a buoyant and sustainable economy. The insecure fuel supply, global warming, high environmental pollution and needs for agricultural products diversification are thundering a race to produce fuel from renewable resources in Nigeria. At her recent sensitisation workshop on biofuels development with the theme, 'Biofuels: Nigeria's New Economy', Nigerian Minister of State for Petroleum Resources, said "Time has come for us to explore alternative energy and revenue sources with the abundance of land and great vegetation available at our disposal" (Biofuel International, 2017). Biodiesel is increasingly being used commercially for transportation to reduce GHG emission, decrease dependence on fossil fuel and support agriculture (World Bank, 2007). Biodiesel is reported to have similar combustion properties as diesel fuel with higher viscosity and octane number and thus considered a clean fuel and rated as a strong alternative candidate for conventional diesel fuel. Other advantages of biodiesel over conventional diesel include its environmental friendliness due to generation of lesser total unburned hydrocarbons and carbon dioxide. Also, pure biodiesel is non-toxic, biodegradable, with lower mutagenicity and therefore, could cause good reduction in cancer risk (Gilman et al., 2014; Tesfa et al., 2014).Nigeria proposed feedstocks for her first generation biodiesels are sugarcane, cassava, sweet sorghum, palm oil, and jatropha. However, some Nigerian chosen biodiesel feedstocks such as palm oil and sweet sorghum have hidden potential to trigger food insecurity in a country such as Nigeria having high percentage of hungry people, recent economy recession, and growing population with increasing demand for food and energy security. Nevertheless, the Estelvina et al. (2011) analysis of the effect of biodiesel on food safety indicates trend of rising food prices with increasing oil prices but not increasing production of biofuel directly due to its insignificant proportion in the world energy supply. Also, they emphasized the indispensable production of biodiesel due to its sustainability as energy is still much food source-dependent. Whatsoever, second generation renewable resources for biofuel are necessary for sustainable development to meet the essential needs of the present generation without compromising the ability to meet the essential needs of the future generations. Waste vegetable oils WVOs are oils that have altered physicochemical properties due to use in batch or continuous processing in food preparations (Gilman et al., 2014). Spent vegetable oils (SpVOs) are type of WVOs that are no longer useful for recycling into food preparations for 
they are no longer healthy and safe for consumption due to high carbon residues and oxidation products that are toxic to human body (Felizardo et al., 2006). The lack of information by the manufacturers makes the consumers directly discard SpVOs in sinks, toilets or even in the rivers and soil, contributing environmental impacts. WVOs have been successful used for production of biodiesel in USA, Canada, China, Austria and Germany (Barabás and Todorut, 2011; SENER, 2017). Nonetheless, SpVOs are promising feedstock for biodiesel production without competition or threat to food security, thereby relieving the burden placed on edible oils and food crops for biofuel production. Proportion of biodiesel generating from SpVOs, though, may not be sufficient but could complement biodiesel as blending agent to lower reliance on food crops and overall cost. In addition, diversifying SpVOs into biofuel production has a potential in reducing environmental impacts of GHG and $\mathrm{CO}_{2}$ emission and thereby translating to safe and healthy environment (Felizardo et al., 2006; Bart et al., 2010). Furthermore, WVOs and SpVOs meet some of the requirement for economic exploitation as cheap raw materials with low cost process (Canakci, 2007; USFDA, 2017). Therefore, as part of concerted efforts in search of complementing non-food bioresources for biodiesel production in Nigeria, the present study assessed the potential of SpVOs as bioresource for FAME production as standard biodiesel using one and two steps transesterification process.

\section{MATERIALS AND METHODS}

All experimental analyses were carried out in the Laboratory of Department of Chemical Sciences, Tai Solarin University of Education, Ijebu-Ode, Nigeria.

Vegetable oils sampling: Vegetable oil feedstocks for FAME production were locally obtained in National Bodija market, Oyo state, Nigeria. Fresh and unused Nigerian palm oil (NPO) and peanut oil $\left(\mathrm{NP}_{\mathrm{e}} \mathrm{O}\right)$ were purchased while Nigerian spent peanut oil (NSPeO) and palm oil (NSPO) were obtained freely from traditional bean cake sellers and restaurants after countless number of reuse for frying and reserved for disposal. Three samples were collected randomly per sub sections within three areas and pooled together per area as replicates, making three replicates for all experiments.

Methanolysis by One and Two steps alkalitransesterification: Clean and unused NPO and NPeO samples were used directly for transesterification process while NSPO and NSPeO samples were heated and filtered to remove any residues from processing and storage and thereafter, washed with warm water by gentle mixing to remove added-spices and left overnight in separating funnel and the water was run off and top-layer clean oil collected. One and two steps alkali-methanolysis for conversion of feedstock into FAME followed Bakir and Fadhil (2011) with modifications. In the one step transesterification, the feedstock were converted into FAME using 6:1 molar ratio of methanol to oil, $1.0 \%$ wt. potassium hydroxide $(0.025 \mathrm{M} \mathrm{KOH})$ pellets as catalyst and transesterification is carried out at $60^{\circ} \mathrm{C}$ over $1 \mathrm{hr}$, considering high AV of the feedstock. The biodiesel filtrate was washed consecutively with dil. $\mathrm{H}_{2} \mathrm{O}$ until neutral to remove residual by-products such as excess alcohol, catalysts, soap and glycerine and then vacuum dried. In two steps alkali-transesterification, biodiesel obtained in the first transesterification was subjected to a second alkali-transesterification under same condition for one step-transesterification.

Characterization of feedstock and FAME: Availability of tools, cost, safety, disposal and health issues were considered for analysis of biofuel characteristics of feedstocks and FAMEs. Specific gravity (SG) was measured using gravimetric method. Density at $15^{\circ} \mathrm{C}$ $\left(\mathrm{g} / \mathrm{cm}^{3}\right)$ was by densimeter according to EN-ISO 3675 . The Kinematic viscosity at $40^{\circ} \mathrm{C}\left(\mathrm{mm}^{2} / \mathrm{s}\right)$ was by Ferranti portable viscometer measurement according to EN 3104. Flash point $\left(\mathrm{FP},{ }^{\circ} \mathrm{C}\right)$ followed D 93 and total water and sediment was by centrifugation as described in D 2709. Sulphated ash (ash, \% mass) followed D 874. Conradson carbon residue $(\mathrm{CC}, \%$ mass) after evaporation and pyrolysis was according to D $189,100 \%$ distribution was estimated for crude feedstocks and $10 \%$ for distilled sample for FAMEs. Total acid value (AV, mg KOH/g) was estimated using macro method of titration after Pr EN 14104. Alkali metals were estimated using the sulphated ash according to EN 14108 and EN 14109 for Na and K, respectively and alkaline metals and heavy metals followed AOAC, 2005 using Atomic Absorption Spectrometer (AAS, Buck Scientific, USA).

Data Management: All data analyses for descriptive, ANOVA, and correlation were carried out using SAS version 9.2 (SAS, 2002).

\section{RESULTS AND DISCUSSION}

Characteristics of $\mathrm{NPO}, \mathrm{NPeO}, \mathrm{NSPO}$, and $\mathrm{NSPeO}$ as biodiesel: Table 1 presents descriptive statistics for the biofuel properties of the assessed feedstocks and reveals higher mean viscosity, AV, FP, CC, ash, water and sediment for all the feedstocks when compared to standard norms for biodiesel (ASTM D6751, EN 14213 and EN 14214). This is no news, for there are several reports on the deficiency of SVOs as direct 
biofuel in diesel engines with regards to their very high viscosity, due to high molecular weight of their fatty acid composition, which increases with increasing carbon chain length and degree of saturation (Altin et al., 2001; Giakoumis, 2013). Higher viscosity, AV, and CC were observed for SpVOs over neat SVOs, which might be due to heterogeneous mixture of the former constituting particulate matter, organic impurities, oxidative degradation and polymerization products (Bart et al., 2010). The very high viscosity of the assessed feedstocks could cause ignition delay due to low volatility and poor fuel atomization, and therefore, they are not suitable in modern directinjector diesel fuel system and engines. Their high FP contributes low volatility not suitable for cold start, and high $\mathrm{AV}$ and $\mathrm{CC}$ will result into carbonisation of injector strips, ring sticking, lubricating oil dilution and degradation. High biofuel characteristic of VOs as presently observed and their aforementioned defects resulted into mechanical damage and engine failure that led to their abandon as straight biofuel (Bart et al., 2010]. Figure 1 shows group I and II metals exceeded values for biodiesel (EN 14214; ASTM D 6751) with exception of NPeME for only group II. Presence of these metals could emanate from diet, manufacturing and food processing of Nigerians and could cause corrosion of combustion chambers (Haseeb et al., 2010).

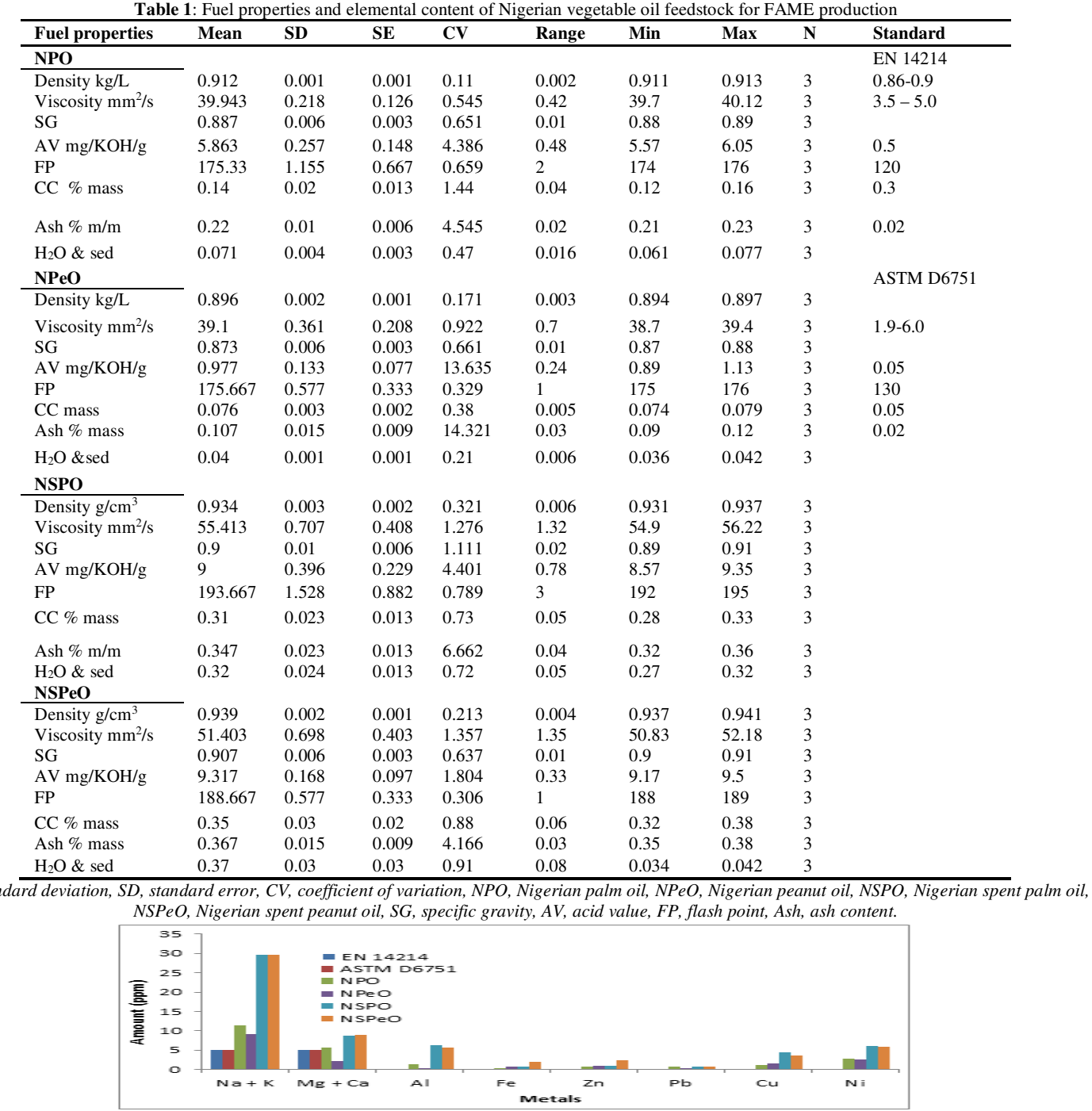

Fig 1: Comparative level of metallic content of NPO, NPeO, NSPO, NSPeO with EN 14214 and ASTM D 6751 standard. NPO, Nigerian palm oil; NPeO, Nigerian peanut oil; NSPO, Nigerian spent palm oil, NSPeO, Nigerian spent peanut oil. 
One step transesterification of $N P O, N P e O, N S P O$, and NSPeO into FAME: biofuel characteristics of $\mathrm{NPO}, \mathrm{NPeO}, \mathrm{NSPO}$, and $\mathrm{NSPeO}$ were improved by conversion into FAME using one step alkalimethanolysis. Based on Fig 2a, FAME from neat SVOs, NPME and NPeME, were within specified biofuel standard except for higher $\mathrm{AV}$ and $\mathrm{CC}$ for NPME while FAME of SpVOs, NSPME and NSPeME exceeded limits. The observed difference in the biofuel properties between FAME from neat and spent vegetable oils could be due to high, AV, FFA and water content characterized of FAME from frying oils (Felizardo et al., 2006; Canakci, 2007; Gashaw and Teshita, 2014). Also, according to Fig 2 (b), the FAME' yield obtained from neat SVOs were higher than those of SpVOs and generally, the present yields were lower to those reported in many literatures (Felizardo et al., 2006; Canakci, 2007; Diya'udeen et al., 2012; Filho et al., 2014). The lower yields obtained at present are indication of incomplete transesterification of glycerides and fatty acids content of the feedstock, which deactivated the catalyst and with formation of soap during transesterification process (Meher et al., 2006). It worth mentioning that the levels of the metals were reduced (data not shown) which might be due to losses of some inorganic salt during washing and neutralisation steps but were not within specified values for group I and II metals. Presence of group I and II metals in fuel could lead to corrosion of the combustion chambers, engine knocking and many mechanical issues cause by high temperature, and their presence might be from adsorption by parent plant from soil, incorporation during oil and food processing or alkali residues in transesterification process (Haseeb et al., 2010) Therefore, one step transesterification caused improved biofuel properties of the SVO on conversion into FAME but biodiesel standards were not met in all FAME produced. In addition, the present yields of
$<80 \%$ are commercially undesirable, compared to $>96.0 \%$ recommended by EN 14214. Many previous reports reveal the advantages of two steps involving acid-esterification for increasing FAME yields and improved biofuel properties for conversion of SVOs, WVOs and SpVOs into biodiesel (Filho et al., 2014; Diya'udeen et al., 2012; Canakci, 2007; Meher et al., 2006). However, the more recent two steps alkalitransesterification, that is akali-alkali transesterification reported by Bakir and Fadhil (2011) showed improved yield and biofuel characteristics over acid-base transesterification and therefore, was employed in further experiment.

Two-steps alkali transesterification of $\mathrm{NPO}, \mathrm{NPeO}$, $N S P O$, and $N S P e O$ into FAME: The present two steps alkali transesterification similar to Bakir and Fadhil (2011) was able to derive FAME within EN 14214 and ASTM D6751 standards but still with higher AV and $\mathrm{CC}$ for NSPME and NSPeME (Fig. 3a). Generally, FAMEs produced possess higher FP. However, FAME with a yield $>80 \%(\mathrm{v} / \mathrm{v})$ was finally obtained (Fig. 3b), which corroborates yields in many similar studies (Felizardo, 2006; Canakci, 2007; Diya'udeen et al., 2012; Filho, et al., 2014). The present mean yields of FAMEs were higher than mean yields of fatty acid ethyl esters (FAEE) obtained from used vegetable oils using silica gel adsorption as post acid-base transesterification treatment by same research team (In press), corroborating Bakir and Fadhil (2011). Figure 4 shows combined alkali metals $(\mathrm{Na}+\mathrm{K})$ was still not generally desirable in all the obtained FAME and alkaline earth metals $(\mathrm{Mg}+\mathrm{Ca})$ also exceeded limit in NSPME and NSPeME (5 ppm in EN 14214; ASTM D6751. Therefore, none of the present FAME produced with two steps alkali-transesterification is a biodiesel according to European norm (EN 14214) considering their metallic content.

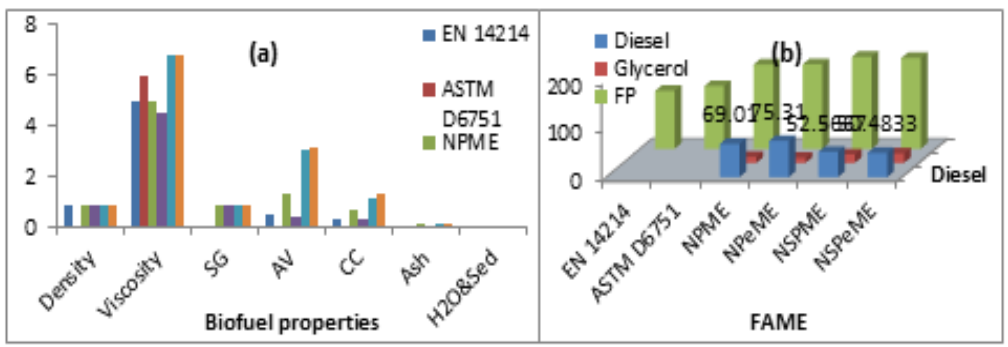

Fig 2: Biofuel properties of derived FAME, NPME, NPeME, NSPME, and NSPeME (a) and Yield of biodiesel, glycerol and FP of FAME (b) in one step alkali-transesterification in comparison with European and USA biodiesel standards. NPME, Nigerian palm methyl ester; NPeME, Nigerian peanut methyl ester; NSPME, Nigerian spent palm methyl ester; NSPeME, Nigerian spent peanut methyl ester; SG, specific gravity; AV, acid value; CC, Conradson carbon residue, ash, sulphated ash; $H 2 O \& S e d$, water and sediment. 


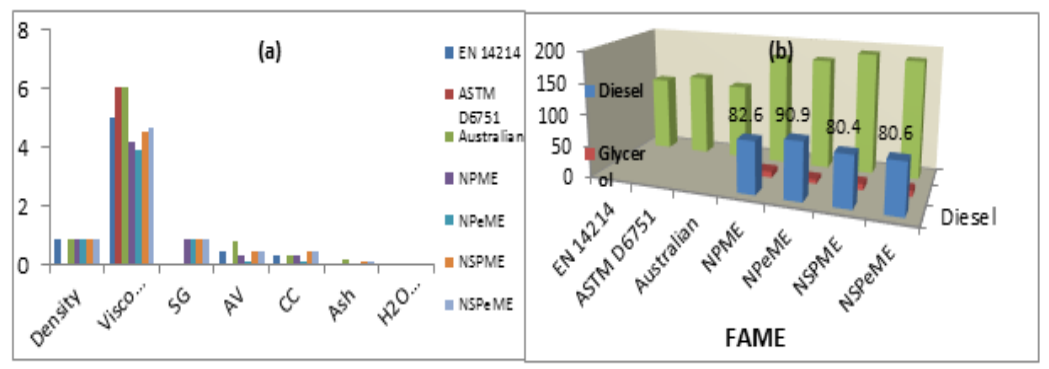

Fig 3: Biofuel properties (a) and Yield of biodiesel, glycerol and FP (b) of NPME, NPeME, NSPME, and NSPeME after two steps alkali transesterification. NPME, Nigerian palm methyl ester, NPeME, Nigerian peanut methyl ester, NSPME, Nigerian spent palm methyl ester, and NSPeME, Nigerian spent peanut methyl ester.

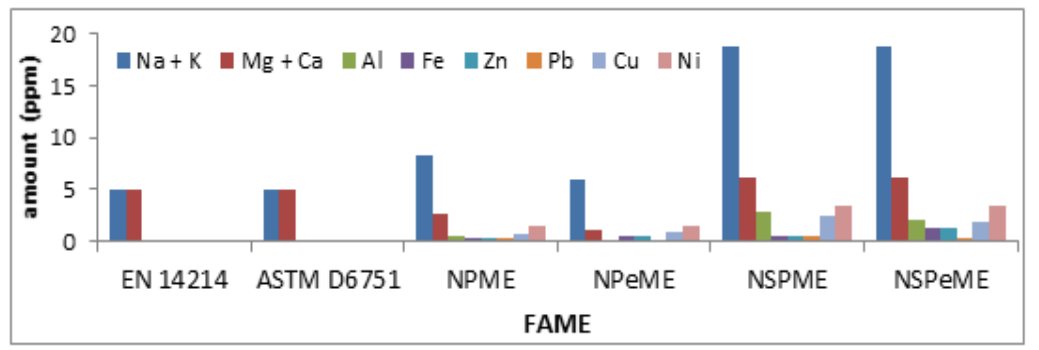

Fig 4: Level of metals in NPME, NPeME, NSPME, NSPeME after two steps transesterification.

Table 2: Pearson Correlations for useful relationships among oil feedstock and Biofuel properties

\begin{tabular}{|c|c|c|c|c|c|c|c|c|c|c|c|c|}
\hline & Density & Viscosity & SG & AV & $\mathrm{FP}$ & $\mathrm{CC}$ & Diesel & Glycerol & Ash & $\mathrm{Na}$ & K & $\mathrm{Mg}$ \\
\hline Freshness? & $0.33^{*}$ & ns & $0.65^{* * *}$ & $0.35^{\circ}$ & $0.96^{* * *}$ & $0.44^{*}$ & $-0.44^{* *}$ & $0.41^{*}$ & $0.40^{* *}$ & $0.73^{* * *}$ & $\mathrm{~ns}$ & $0.54^{* * *}$ \\
\hline Density & 1 & $0.84 * *$ & $0.84^{* * *}$ & $0.93^{* * *}$ & $0.47^{* * *}$ & $0.93^{* * *}$ & $-0.89^{* * *}$ & $0.85^{* * *}$ & $0.96 * *$ & $0.76^{*+*}$ & $0.87^{* * *}$ & $0.83^{* * *}$ \\
\hline Viscosity & & 1 & $0.68^{* * *}$ & $0.86^{* * *}$ & ns & $0.84^{* * *}$ & $-0.97^{* * *}$ & $0.95^{* * *}$ & $0.83 * *$ & $0.47^{* * *}$ & $0.74^{* * *}$ & $0.61 * *$ \\
\hline SG & & & 1 & $0.83^{* \cdots}$ & $0.70^{* \cdots}$ & $0.85^{* * *}$ & $-0.63^{* * *}$ & $0.60^{* * *}$ & $0.85^{* * *}$ & $0.83^{* * *}$ & $0.66 * * *$ & $0.82 * * *$ \\
\hline AV & & & & 1 & $0.48 * \cdots$ & $0.97^{* * *}$ & $-0.96^{* * *}$ & $0.96^{* * *}$ & $0.97^{* * \bullet}$ & $0.74^{* * *}$ & $0.74 * * *$ & $0.83^{* * *}$ \\
\hline $\mathrm{FP}$ & & & & & 1 & $0.56^{* * *}$ & $-0.51^{* \bullet}$ & $0.49^{* *}$ & $0.53^{* * *}$ & $0.82^{* * *}$ & $0.43^{* *}$ & $0.65^{* * *}$ \\
\hline $\mathrm{CC}$ & & & & & & 1 & $-0.96^{* * *}$ & $0.95^{* * *}$ & $0.97^{* * *}$ & $0.80^{* * *}$ & $0.77^{* * *}$ & $0.84^{* * *}$ \\
\hline Diesel & & & & & & & 1 & $0.98^{* * *}$ & $0.89 * *$ & $-0.73^{\bullet \bullet \bullet}$ & $0.69^{* * *}$ & $0.76^{\circ * *}$ \\
\hline Glycerol & & & & & & & & 1 & $0.87^{* * \bullet}$ & $0.72^{* \cdots}$ & $0.65^{* * *}$ & $0.72 \cdots$ \\
\hline Ash & & & & & & & & & 1 & $0.83^{* * *}$ & $0.82^{* * *}$ & $0.89^{* * *}$ \\
\hline $\mathrm{Na}$ & & & & & & & & & & 1 & $0.72^{* * *}$ & $0.89^{* * *}$ \\
\hline K & & & & & & & & & & & 1 & $0.70^{* * *}$ \\
\hline $\mathrm{Mg}$ & & & & & & & & & & & & 1 \\
\hline
\end{tabular}

Freshness, from clean neat SVOs to NSpVOs, $* p \leq 0.05, * *, p \leq 0.01$, ***, $p<0.001$, ns, non-significant

Useful relationships among the yield and biofuel properties of FAME: Pearson correlation relationships in Table 2 shows freshness of feedstock was strongly related to fuel properties and metal content and also, three were high significant defences in biofuel properties of feedstock and FAME produced. Therefore, as neat VO move to SpVO, there is increasing density, SG, AV, CC and metal content but with decreasing yield of diesel. There was no significant difference in biofuel properties of FAME from neat VOs and SpVOs. Generally, the biofuel properties of generated FAME were strongly correlated with one another, and yield of glycerol, alkali and alkaline metals but were inversely correlated with yield of FAME. Therefore, the higher the viscosity of feedstock /FAME, the higher the other biofuel properties and glycerol content but the lower the yield of biodiesel. The present result was able to statistically reveal the observed differences in biofuel properties, and yield of biodiesel previously reported in similar studies [Barabás and Todorut, 2011; Giakoumis, 2013). High viscosity has been previously linked to high AV, CC, ash content in WVOs due to oxidation, pyrolysis of fatty acids and glycerides to produce oxidative biodegradation and polymerization products that are contaminants in biodiesel (Giakoumis, 2013).

Conclusions: Diversification of spent palm and peanut oils as non-food option for biodiesel production to 
avoid burden on food security crops and achieve low carbon footprint is well feasible and achievable as experimented in the present study. However, their conversions into neat and clean biodiesel require two steps transesterification other than one step alkali transesterification process. Also, there is need for post two steps transesterification treatment to meet Intentional biodiesel standards. Further investigation was carried out to assess the potential of waste printing paper (WPP) to adsorb metals from the present generated FAME and the results generated shall be reported as Part II in a new paper.

\section{REFERENCES}

Altin, R; Çentinkaya, S; Yucesu, HS (2001). The potential of using vegetable oil fuels as fuel for diesel engines. En. Conv. Managm. 42: 529-538.

Bakir, ET; Fadhil, AB (2011). Production of biodiesel from chicken frying oil. Pak. J. Anal. Environ. Chem. 12 (1 \& 2): 95-108.

Barabás, I; Todorut, A (2011). Biodiesel quality, standards and properties. Ch. 1. In: Montero G; Stoytcheva M (eds) Biodiesel, quality, emissions and by-products. InTech, Rjeka, Croatia. p.3.

Bart, JCR; Palmeri, N; Cavallaro, S (2010). Biodiesel Science and Technology- From soil to oil, $7^{\text {th }}$ Series, Wood Head Publishing limited, Cambridge CB21 6AH UK. 2010.

Biofuels International Magazine, Woodcote Media Ltd, Surrey, Nigeria eyes biofuels push, 2017. http://biofuels-

news.com/display_news/11830/Nigeria_eyes_biofu els_push/2017, (accessed 20 May 2017).

Canakci, M (2007). The potential of restaurant waste lipids as biodiesel feedstocks. Bioresour. Technol. 98: 183-190.

Diya'udeen, BH; Abdul-Aziz, AR; Daud, WMAW; Charabarti, MH (2012). Performance evaluation of biodiesel from used domestic waste oils: A review. Process Safety and Environmental protection 90P: 164-179

Felizardo, PM; Correia, J; Raposo, I; Mendes, JF; Berkemeir, R; Boedado, JM (2006). Production of biodiesel from waste frying oils. Waste Manag. 26: 487-494.

Filho, SCS; Silva, TAF; Miranda, AC; Fernandesa, MPB; Felico, HH; Calarge, FA; Santana, JCC; Tambourgi, EB (2014). The potential of biodiesel production from frying oil used in the restaurants of São Paulo City. Brazil. CET 37: 577-582
Gashaw, A; Teshita, A (2014). Production of biodiesel from waste cooking oil and factors affecting its formation: A review. International Journal of Renewable and Sustainable Energy 3: 92-98.

Giakoumis, EG (2013). A statistical investigation of biodiesel physical and chemical properties, and their correlation with the degree of unsaturation. Renew. Energy 50: 858-878,

Gilman, I; Demarini, D; Kodavanti, U; Fukufawa, N; Fanaj, A; Hazari, M; Gavete, S (2014). EPA Science Inventory 22-26. http://cfpub.epa.gov/si/si_public_record_reprot.cfm ?dirEntryid=270693, (accessed 9 October 2017).

Haseeb, ASMA; Masjuki, HH; Ann, LJ; Faza, MA (2010). Corrosion characteristics of copper and leaded bronze in palm diesel. Fuel Process. Technol. 1(3): 329-334

Meher, LC; Sagar, DV; Naik, SN (2006).Technical aspects of biodiesel production by transesterification- a review. Renew, Sustain, Energy Revs. 10: 248-268.

Perrier, X; Jacquemoud-Collet, JP (2006). DARwin software. http://darwin.cirad.fr/darwin.

SENER (2006b). Balanced Nacional de energia, SENER, Mexico. http://www.sener.gob.mx/webSener/portal/index.jsp?id=48. (Accessed 23 May 2017).

Statistical analysis system (SAS) (2002) Version 8. SAS Institute Incorporation, NC Cary.

Tesfa, B; Gu, F; Mishra, R; Ball, A (2014). Emission characteristics of a $\mathrm{CI}$ engine running with a range of biodiesel feedstocks. Energies 7: 334-350.

US Food and Drug Administration (USFDA) (2017). Substances prohibited from use in animal food and feed. Code of Federal Regulations 21 CFR Part 589. Fed. Regist. 62, 30935-30978. USA

World Bank. (2007). Agriculture for development. World development report. The World Bank, Washington DC. http://siteresource.worldbank.org (accessed 17 March 2017). 